\title{
A CIDADE E OS SEUS RISCOS: O VIVER DE DEFICIENTES VISUAIS EM PORTO ALEGRE.
}

Sandro Belloli Rillo

Cornelia Eckert (orientação)

\section{Introdução}

Esta pesquisa vem sendo desenvolvida desde os meses finais do ano $2000 \mathrm{e}$ encontra-se hoje em andamento. Eu, Sandro Belloli Rillo, na qualidade de bolsista de iniciação científica que estou desenvolvendo, conto para isso com a oportunidade de trabalhar no Navisual, Núcleo de antropologia visual da Universidade Federal do Rio Grande do Sul(UFRGS), onde a Prof. Dra Cornelia Eckert possui um projeto como o nome de "Estudo antropológico de itinerários urbanos, memória coletiva e formas de sociabilidade no meio urbano contemporâneo" ao qual minha pesquisa está vinculada e sob sua orientação.

Dentro deste universo de estudo proposto desenvolvo minha pesquisa, tentando mostrar como a cidade de Porto Alegre, onde sou morador, é vista, sentida, descrita e percebida por habitantes que com ela interagem, cotidianamente, criando trajetos e tecendo projetos individuais, através de suas histórias particulares mesmo sem vê-la. Ou pelo menos não a vendo da maneira que a maioria dos pedestres que passeiam pelas ruas vêem, mas independente da falta de visão esses portadores de deficiência criam com a cidade laços de afetividade e pertencimento ou de tensão e de critica como qualquer pedestre.

A imagem da cidade não é privada aos que têm visão. Aprendi no decorrer da minha pesquisa que mesmo as pessoas que não possuem visão, mas têm uma vida social, criam uma imagem da cidade em que residem, seja esta construída através de suas histórias de vida, do nível de informação que possuem, das rotas traçadas para o próprio deslocamento dentro da cidade em função de uma estética pratica, ou mesmo dos laços de afetividade que o portador de deficiência cria, particularmente, com partes desta.

Os deficientes visuais possuem uma imagem da cidade onde moram, o que os diferencia é que constroem uma imagem da cidade sem vê-la, mas através dos demais sentidos como o tato e a audição que singularizam sua forma de apropriar-se da cidade.

O problema de pesquisa consiste, então, em tentar desvendar como os deficientes visuais moradores de Porto Alegre criam a imagem da cidade onde moram. 
Importa esclarecer quanto ao grupo pesquisado que inclui-se na categoria deficiente visual, tanto pessoas que nasceram com esta deficiência, como também pessoas que por algum outro motivo, como por exemplo, acidente ou doença encontram-se também com a mesma deficiência. Da mesma forma importa esclarecer que foram entrevistados deficientes visuais que são moradores na região metropolitana da cidade e desenvolvem atividades comerciais, ou então, esmolam e dependem do comércio que é desenvolvido no centro desta cidade.

O problema de pesquisa foi sugerido pela minha orientadora, que como já disse, coordena um projeto maior de antropologia urbana na cidade de Porto Alegre, através de pesquisa sua ou pesquisas sob sua orientação, na Universidade Federal do Rio Grande do Sul. No âmbito deste projeto maior que está inserido minha pesquisa, ainda não havia sido feito nenhum estudo com deficientes visuais moradores de Porto Alegre, o que significa que eu não possuía alguma referência quando aceitei a proposta de tentar desenvolver o tema. Mas, mesmo não tendo referência aceitei desde o primeiro instante, porque, no mínimo, seria interessante tentar descobrir como um deficiente visual "conhece" a cidade da qual faz parte. Além disso era a oportunidade que eu tinha de trabalhar, na área de estudo que pretendo me formar. Curso Ciências Sociais na Universidade federal do Rio Grande do Sul.

\section{A inserção no universo de pesquisa}

Aceitando a proposta de trabalhar com este tema, iniciei a pesquisa em novembro 2000 buscando conhecer primeiramente as escolas especializadas em alfabetizar deficientes visuais, na busca de tentar meus primeiros contatos com o grupo que eu iria estudar. Através da indicação de um tio, que é motorista de táxi em Porto Alegre, certifiquei-me de que na rua da República, no bairro Cidade Baixa, havia uma escola deste tipo. Uma escola que alfabetizava deficientes visuais. Fui até esta escola para conversar como a direção do estabelecimento na tentativa de saber qual a possibilidade de serem realizadas entrevistas com alguns alunos.

Dona Vilma foi quem me atendeu, e quem me deu as primeiras explicações a respeito do funcionamento desta escola. A escola, segundo as declarações da Dona Vilma, alfabetizava crianças que nasciam com deficiência visual, além de também trabalhar com adultos que tornaram-se deficientes após algum tipo de acidente ou doença, para quem a escola tem uma função de reintegração social, através dos ensinamentos especializados que buscam dar uma maior autonomia ao deficiente visual para tarefas do lar, ou profissionalizantes. Ensinam deficientes visuais a passar roupas, por exemplo, ou então a se locomover dentro de um banheiro, no caso de um deficiente que não nasceu com o problema. Além disso, há programas 
profissionalizantes, onde são dadas aulas de digitação e informática, nesta última, os alunos são ensinado a usar programas especialmente desenvolvidos para deficientes visuais.

Dessa forma o público que freqüenta esta escola é bastante heterogêneo, o que incluí pessoas de diferentes idades e situações sociais, em torno do problema da deficiência visual, apesar de a primeira vista o público da escola aparentar, majoritariamente, representantes de classe média

Devido a tentativa de outros pesquisadores de trabalhar dentro do Centro Braile, a direção da escola não via com bons olhos minha presença lá. Dona Vilma achava perigoso algum aluno não gostar que um estranho o perguntasse o que ele achava da cidade de Porto Alegre, e fosse comunicar a direção. Dessa forma não fui aceito nas minhas primeiras tentativas de entrar em contato com algum deficiente visual, mas mesmo assim voltei algumas vezes.

Lembro uma vez que eu aguardava, na sala de espera, uma assistente social que lá trabalhava para conversar a respeito da minha aceitação na escola. A assistente demorou muito e então começaram a chegar alunos para o próximo horário. Estes chegavam sempre acompanhados por pais ou responsáveis que lhes conduziam a porta da escola, devido a pouca idade desta turma, e também, é claro, pelo motivo da deficiência. Logo me vi cercado de deficientes visuais, todos deveriam ter entre dez e treze anos de idade e aguardavam o início da aula.

- "Pedro você está ai?" Perguntava a menina que mais falava dentre os alunos. Toda vez que abriam a porta ela escutava o barulho desta, e queria saber quem era que estava entrando, se era seu colega ou quem quer que fosse. "O Pedro não está ai, ou ele não quer falar porque o time dele perdeu ontem?" Perguntou a menina em tom provocativo. Pedro estava sentado do meu lado, e não estava com cara de quem queria falar. - "Acho que o gato comeu a língua dele", falou novamente a mesma menina. - "Ele está triste". Respondeu outro colega que estava na sala. “Tem mais alguém contigo?" Perguntou ela, e eu respondi que sim. Na mesma hora em que a menina escutou a minha voz, assustou-se e perguntou quem eu era. Pensavam que estavam sozinhos na sala. Falei que estava aguardando a assistente social e que era estudante. A menina acalmou-se, no meio do silêncio que todos os presentes fizeram ao escutar minha voz, e a assistente social logo apareceu perguntando quem a aguardava, falei que era eu, e ela pediu-me para que passasse pela porta que estava ao lado para não atrapalhar a aula que iria começar.

Minha permanência no Centro Braile foi curta, apesar de eu tentar envolver-me com os alunos que lá estudavam, a direção da escola não aprovou minha presença, então acabei afastando-me. Eu estava com um problema que era o de conseguir aproximação do grupo que eu iria estudar, minha primeira tentativa pelo visto havia falhado e eu tinha que conseguir outras formas de aproximação dos deficientes visuais. 


\section{Conhecendo André}

Fragmentos de diario de campo: "Subi e o André estava sozinho, diferente do primeiro encontro, quando fui à sua casa e me deparei com alguns conhecidos do curso de Ciências Sociais. Antes de abrir a porta ele fez o mesmo ritual que havia feito na outra visita. Abriu primeiramente uma espécie de janelinha que há na sua porta para identificar quem está batendo. E quando ele fez isso pela primeira vez, eu lembro que me marcou bastante porque essa janela fica na altura dos olhos, e eu sem saber, aproximei-me para poder enxergar dentro da casa e fiquei praticamente cara a cara com os olhos do André. -Olhos não, tecido morto (descrição científica como André se refere a seus olhos). Tem alguém contigo? Perguntou ele. Não, respondi. Tem certeza? Pergunta ele em tom irônico já abrindo a porta."

Certa vez eu andava na rua Osvaldo Aranha, bairro Bonfim, quando de longe avistei um conhecido, que também estuda Ciências Sociais, andando na calçada guiando um deficiente visual pelo braço. Não falei nada naquele momento, esperei encontrar novamente o meu conhecido para perguntar a respeito do rapaz que ele guiava. Quando encontrei o Felipe novamente perguntei a ele quem era o rapaz deficiente visual que ele acompanhava. Felipe falou-me que o rapaz chamase André e que este teria sido nosso colega, durante pouco tempo, no curso de Ciências Sociais. Mas que no momento eles dividiam o aluguel de um apartamento no bairro Cidade Baixa, local onde se localiza também a escola de Braile. Felipe deu-me o telefone da casa onde eles moram para que eu pudesse falar pessoalmente com o André. Então liguei, falei com o André e marcamos minha primeira entrevista, minha orientadora estava presente nesta entrevista, que realizou-se na sua casa. Eu e o André fomos até a sua casa de carro, pois embora deficiente, André possui um carro que seus amigos dirigem para ele melhor deslocar-se dentro da cidade. Foi seu amigo Lourenço, outro rapaz que divide o apartamento com André e Felipe que nos conduziu à casa de minha orientadora.

Através desta primeira entrevista minha pesquisa desenvolveu-se mais facilmente. O contato com o André fez com que eu tivesse maior possibilidades de ampliar minhas relações com o grupo de deficientes visuais. Após esta entrevista falei com o André mais vezes, inclusive freqüentando sua casa para fazer-lhe visitas e dialogar.

E foi através do circulo de amizade do André que dei continuidade a minha pesquisa. Este forneceu-me telefones de amigos seus, que também são deficientes visuais, e segundo ele, estariam interessados em contribuir para meus estudos, assim, aos poucos, fui aumentando o meu universo de pesquisa através de seus conhecidos. 


\section{Conhecendo Renato}

Fragmentos de diário de campo:

\footnotetext{
"Cheguei a frente do apartamento indicado e apertei a campainha. Logo a porta se abriu e apareceu a minha frente uma mulher de óculos escuros, aparentemente, deficiente visual e esposa de Renato. Dona da voz feminina que atendeu minha ligação, pensei. - Pode passar, falou ela quando do corredor avistei Renato, vindo em minha direção convidando-me para adentrar na casa. Fui andando atrás dele que movimentava-se rapidamente dentro de casa, as vezes até parecendo-me um pouco nervoso, quando vi que na cozinha a esposa de Renato não estava sozinha. Tinha a companhia de uma mulher que possivelmente a ajudava no preparo da comida, pois pelo que eu pude ver, portava uma faca de cozinha nas mãos."
}

Dos telefones que me foram cedidos consegui entrar em contato com Renato, com que fiz uma segunda entrevista, e com quem mantenho contato até hoje .Tornou-se um amigo via email, semanalmente manda mensagens para mim. Mensagens de assuntos dos mais diversos, como por exemplo, política, devido a sua militância contra a corrupção dos cargos públicos, envia notícias que mostram o desvio de dinheiro público, onde estão envolvidos políticos eleitos através do voto do povo. Ou então mensagens que falam a respeito de educação e preservação ambiental

\section{Personagem 1: André, estudantes de Ciências Sociais}

Dentro desta que chamarei de primeira parte da pesquisa, foram entrevistados dois portadores de deficiência visual. Nesta primeira parte usei a observação participante, diálogos, conversas e técnicas de entrevista aberta para montar meus diários de campo e trabalhos.

O primeiro entrevistado foi André Luis Lima, 36 anos, agrônomo formado pela Universidade Federal do Rio Grande do Sul (UFRGS). Nasceu em Porto Alegre, mas só foi morar nesta cidade quando passou no vestibular para agronomia, e transferiu-se para casa do estudante. Antes disso morava em Canoas, região metropolitana da cidade de Porto Alegre. Depois de um acidente automobilístico, no ano de 1988 perdeu a visão, nesta situação já havia se formado, frequientou o Centro Braile, do bairro Cidade Baixa, onde diz ter se reintegrado à sociedade como um deficiente visual, aprendendo a usar programas de computador especiais para deficientes visuais, o que objetivaria uma nova profissão, e também atividades práticas como andar de bengala e pequenas tarefas do lar, que foram citadas anteriormente. Hoje é funcionário público concursado, trabalha com informática na sua repartição.

Por ocasião da última entrevista, contou-me da vontade de sair do seu emprego, e dava como certo seu pedido de demissão. É provável que ele não seja mais funcionário público. 
Reside no bairro Cidade Baixa, por motivos de proximidades da região central da cidade e do seu emprego, além disso, o bairro Cidade Baixa tem uma vida cultural e muita diversão noturna, freqüentado por universitários e boêmios, representantes da classe média porto-alegrense. André mora de aluguel com mais dois amigos, que são estudantes de Ciências Sociais, através dos quais cheguei até ele. Possui um carro para melhor se locomover na cidade e também para ir ao litoral durante o verão. Não é casado, não tem filhos, e o curso de Ciências Sociais seria sua segunda formação. Foi através deste curso que conheceu os colegas com quem divide apartamento. Quanto a sua posição política se diz de esquerda, e, ultimamente está insatisfeito até com os partidos que se dizem representantes desta corrente, principalmente com a administração do PT em Porto Alegre, que segundo ele "só é popular na teoria”

\section{Personagem 2: Renato, 0 intelectual de esquerda}

O segundo entrevistado é Renato Santana, 40 anos, psicólogo formado pela PUC de Pelotas, veio à Porto Alegre para trabalhar, isso já fazem doze anos. Mora no centro da cidade, na rua Riachuelo, por motivos de deslocamento, caso morasse em outro lugar de Porto Alegre teria que usar transporte coletivo para ir ao trabalho, e isso ele diz que não suporta. Faz o trajeto da sua casa ao trabalho andando, o que segundo ele seria muito melhor caso a cidade não tivesse tanto ruído, e se as demais pessoas respeitassem o passeio público, deixando-o livre. É casado, mora com a esposa e tem uma empregada doméstica para ajudar nas tarefas do lar. Não possuí carro nem filhos e trabalha na Secretária da Saúde, onde exerce a profissão de psicólogo. Quanto a sua posição política, se diz uma pessoa de esquerda, e conceitua tal situação mostrando sua insatisfação com a forma atual de gestão política realizada pelos partidos de direita no Brasil. Quanto a administração, "democrática e popular", do PT em Porto Alegre, Renato vê com bons olhos, diz que muita coisa melhorou nestes anos. Conheceu o André através do Centro Braile, onde era instrutor de informática quando este lá chegou, após o acidente que o fez se tornar um deficiente visual.

\section{O relato de André e Renato e a relação com Porto Alegre}

Fomos a um bar, eu e o André, após a ocasião da entrevista, juntamente com alguns amigos da faculdade. A convivência com o André era bastante facilitada devido a sua idade e ao seu círculo de amizade ser composto por universitários, assim era fácil encontrá-lo em locais que freqüentava. Porém devido a sérios problemas psicológicos que ele enfrentava, e também a má relação que possuía no seu emprego, acabamos não nos encontrando mais. Diferente 
do que aconteceu como o Renato, pessoa com quem mantenho contato regularmente, através da internet, sendo isso possível devido a um programa de computador que fala o que está sendo digitado na tela, dando plenas condições para o deficiente visual usar este aparelho.

O perfil dos meus primeiros entrevistados assemelhava-se em muitos pontos. Os dois têm aproximadamente a mesma idade, ambos com curso superior, moram próximo um do outro, se intitulam como "de esquerda", são funcionários públicos e representantes de um mesmo estrato social. $\mathrm{Ou}$ seja, representam o estrato social classe média com nível universitário, que tem condições de pagar aluguel perto do emprego evitando assim, o transtorno no deslocamento diário. Ou então como o André, que compra um carro para que seus amigos o levem para onde precisa ir, evitando desta forma, os transtornos de uma estética urbana que não privilegia os deficientes visuais.

Nas entrevistas que fiz com estes dois deficientes, não obtive respostas muito agradáveis quanto a cidade de Porto Alegre, e de certa maneira estas foram muito parecidas. Tanto o André quanto o Renato não se sentem contemplados, ou reconhecidos, pelas políticas de urbanização implementadas na cidade. Falam de uma falta de respeito com o passeio público, tanto das autoridades políticas que não se preocupavam em colocar rampas de acesso, ou corrimãos, como também, dos demais transeuntes que não se importam se há pedestres que não possuem visão, e ocupam vias públicas da cidade, sem saber o quanto isso atrapalha o caminhar de um deficiente visual.

Neste sentido relata André:

"Eu conheci vária pessoas que sofreram acidente de carro e que não saíram mais de casa. A decisão que eles tomaram foi de não sair mais. Depois que eu comecei a freqüentar o Braile (Centro) eu conheci muitas pessoas deste tipo, e eu não vou dizer a eles que a minha vida é certa. É comum você estar andando na cidade e escutar brincadeiras do tipo: E aí ceguinho?, outras pessoas dão risadas da tua cara. Gente que passa por ti e não oferece ajuda para atravessar a rua." André Luis Lima

A narrativa de Renato se aproxima da anterior:

"Eu tenho que me deslocar e atravessar o centro da cidade, pois eu moro aqui na Riachuelo e trabalho perto da Rodoviária. Mas eu vou a pé, normalmente, e acho que é necessário ir a pé.

Pesquisador: E neste caminho?

R: Esse caminho é irritante porque eu tenho que fazer um esforço muito grande. Se não houvesse gente na rua eu faria esse trajeto em vinte minutos e normalmente eu faço em um pouco mais de trinta minutos. Daqui até lá todo o ambiente é cheio de obstáculos e com excesso de ruído. Muita banca de camelô no caminho, muita surpresa do tipo "um papeleiro deixa um carro com aquela alça erguida para bater no rosto da gente". Coisas que deixam no caminho hoje, 
que ontem não estavam. Enfim uma série de coisas que me atrapalham, e principalmente o ruído que me atrapalha e me impede de detectar esses obstáculos" Renato Santana.

Pode-se sugerir, através destes depoimentos, a importância da estética funcional da cidade para o deslocamento dos deficientes visuais. Pois é através desta funcionalidade que eles se apropriam dos lugares da cidade e a partir do qual identificam seus pertencimentos e evitações.

\footnotetext{
"Quando tu enxerga é dado muito valor para a estética visual do objeto, se um prédio é bonito, se um orelhão é vermelho. Para mim agora a estética é funcional. O orelhão faz eu bater? Então para mim esteticamente ele é ruim. Se a calçada é bonitinha mais é cheia de desníveis, a estética dela para mim é ruim. Ela pode até ser muito bonita visualmente mais para mim complica. Um toldo pode ser muito bonito em um bar, mas eu bato a cabeça nele então para mim ele é uma merda. A estética passa a ser bem mais funcional do que visual." André Luis lima.
}

Para André, a estética da cidade transformou-se de uma estética visual (em que esta em jogo a contemplação das partes desta), para uma estética funcional, onde o que importa não é mais a beleza da cidade e sim a funcionalidade para tal grupo.

Assim, a imagem da cidade que tive destes entrevistados foi a de que partes públicas da cidade acabam se tornando uma tortura para estes deficientes, fazendo com que mudem seus projetos individuais de vida, tentando evitá-las de qualquer forma. Tanto o André quanto o Renato disseram que mudaram-se para o centro da cidade por motivos de proximidades do trabalho, desta forma evitam pegar ônibus e conviver com um ambiente que não faz bem a eles. Renato, apesar de morar nas proximidades do Teatro São Pedro, diz que prefere não ir até lá para não se sentir constrangido com a ajuda de flanelinhas que o arrastam de maneira inconveniente até a porta do local, fazendo com que este chegue ao teatro com marcas de mãos no casaco.

Dentro dos projetos de vida destes deficientes, que como o Renato, veio a Porto Alegre ter melhores oportunidades de emprego, está incluído o distanciamento de partes públicas da cidade através de uma percepção de individualidade possuída por eles. André, por exemplo, comprou um carro para seus amigos o levarem para onde precisa e para não precisar usar transporte coletivo, onde se sentiria mal.

\section{A pesquisa no centro de Porto Alegre}

"Pesquisador: E essa amizade de vocês, deficientes visuais, aqui no centro?

$\mathrm{W}$ : Exato nós temos um grupo que se reúne para tomar um cafezinho, sentar, conversar sobre política, futebol e brincadeiras. Porque geralmente o deficiente tem uma particularidade, ele é muito bem humorado, sabe. Então a gente tá sempre brincando 
P: Isso faz com que no final da tarde vocês sempre se juntem?

W: Exato. Cinco horas é sagrado a gente sempre se reúne para tomar um cafezinho ali no bar da esquina. O bar do Baldarate, ali é sagrado. Vamos ali todos os dias.

P: O centro aqui de Porto Alegre, o que você acha?

$\mathrm{W}$ : Eu particularmente gosto muito daqui do centro. Não tenho dificuldade. Eu acho uma cidade muito bonita, e gosto muito aqui do centro. Wilson Borba, 39 anos, deficiente visual vendedor de bilhetes lotéricos na esquina democrática.

$\mathrm{Na}$ segunda parte do meu trabalho busquei inserir-me em um ambiente caracterizado pela presença de um grupo com características diferenciadas do grupo social ao qual André e Renato pertencem. Anteriormente eu pesquisava dentro de um grupo de deficientes visuais pertencentes a um estrato social representado por indivíduos de classe média. Não que eu esteja afirmando que estou fora deste grupo, muito pelo contrário, a realidade social vivida por André e Renato é a mesma da qual faço parte. Assim como eu, o André estudava na UFRGS e freqüentávamos os mesmos lugares. O que eu quero dizer é que como pesquisador, também estou incluído dentro do meu universo de estudo, e por isso talvez, entendesse com facilidade as críticas intelectuais feitas por meus entrevistados a respeito da imagem da cidade de Porto Alegre.

$\mathrm{Na}$ segunda parte da minha pesquisa consegui contato com um grupo de deficientes visuais que trabalha na economia informal desenvolvida no centro da cidade de Porto Alegre, conseguindo desta forma uma maior estranhamento ao meu próprio grupo de pertencimento.

São vendedores de bilhetes, preferencialmente, com que convivi tentando descrever o ambiente onde o grupo trabalhava, seus percursos e rotinas no centro da cidade, sendo estas relatadas em meu diário de campo através de observações, conversas, participações, notas e entrevistas transcritas.

O centro da cidade de Porto Alegre não é no centro. É a primeira constatação que faço pois, apesar de ter nascido em Porto Alegre moro aqui há apenas três anos. Morei muito tempo em Brasília, e por isso noto com facilidade que aquilo que os portoalegrenses chamam de centro, é o extremo da cidade e localiza-se nas margens do lago Guaíba. Outra característica peculiar ao centro de Porto Alegre é a de que há ruas onde carros não passam, tornando-se ruas preferências para as pessoas que trabalham na economia informal, não que o comércio informal só ocorra aí, mas há uma preferência lógica dos trabalhadores por essas vias.

Estas ruas tornam-se focos de camelôs não regularizados, bilheteiros, 
vendedores de lixa, vendedores de relógio, óculos, despertadores, pilhas, bonecas, facas, escova de dentes, imitações de roupas de grifes famosas, bateria de relógio, perfumes, creme de barbear, sapato, paletó usado e etc. Todo este material é exposto em pequenas armações de madeira que os vendedores carregam embaixo do braço, e que se transforma em uma espécie de mini-mesa, fixada no local de venda, servindo de apoio ao material que será exposto sob uma toalha. Outros preferem expor suas "mercadorias" apenas sobre uma fina toalha no chão. Todo este aparato é justificado pela situação irregular destes vendedores, que ao menor aviso de que o "pessoal da Smic tá na banda", tem que rapidamente guardar seus produtos sob pena de ficar sem eles, caso sejam pegos vendendo sem autorização.

Quando o pessoal da Smic está no centro é surpreendente ver a rua dos Andradas sem nenhum ambulante. Esta rua por ser a rua mais famosa do centro de Porto Alegre, e por ter trechos onde não passam carros, é uma rua de grande preferência dos vendedores ambulantes. A preferência da Smic por fiscalizar a Andradas, faz como que nos dia de fiscalização ruas vizinhas a ela se tornem superlotadas por ambulantes. É uma espécie de perseguição no centro da cidade. Cabe assinalar que geralmente a Smic fiscaliza apenas poucos trechos, forçando uma rápida transferência dos ambulantes que ali trabalhavam, causando superlotação em outras ruas, pois os ambulantes apenas mudam de local momentaneamente enquanto a Smic fiscaliza

Uma das ruas próxima a rua dos Andradas, e que costuma ter seu fluxo aumentado quando a Smic está fiscalizando, é a rua Floriano Peixoto, esta situa-se perpendicularmente a rua dos Andradas, e está sempre repleta de vendedores ambulantes. Perguntei a um deles se naquela rua passavam carros, e o rapaz não soube me responder, falou que trabalhava na Andradas e que devido ao pessoal da fiscalização estar lá, ele havia se mudado para esta rua. O Paraguai”, como por exemplo, CDs e fitas de vídeo, ficando expostos em uma toalha no chão. Devido ao grande número de ambulantes nesta rua os lojistas colocam seus vendedores com microfones, no meio da rua, como uma forma de bater a grande concorrência que localiza-se na frente de suas lojas. Estes vendedores têm a função de atrair a "clientela".

Continuando na rua Floriano Peixoto noto que há uma grande parte de prédios históricos nesta rua, mas estes localizam-se apenas na parte de cima das lojas, ou seja, na sobreloja. Traços de uma arquitetura antiga e sinal de que a cidade está em um movimento constante de renovação, onde formas novas de arquitetura assumem papel principal, na transformação do urbano através de valores estéticos representantes de uma época. 
Através do meu primeiro entrevistado bilheteiro fui levado a rua Otávio Rocha. Wilson chama-se ele. Através dele, ou atrás dele, que comecei minhas entrevistas com deficientes visuais que trabalham no centro de Porto Alegre. Este rapaz sempre vende bilhete no centro da cidade, durante a semana, e eu a partir do momento que o conheci, comecei a observar quais pontos do centro ele tinha preferência para trabalhar. Pois bem, o Wilson vende bilhetes na esquina democrática, ponto de encontro da rua dos Andradas com a Avenida Borges de Medeiros, ou então na frente do Banrisul da Otávio Rocha, preferencialmente, mas já o encontrei em diversos pontos do centro da cidade. Mas foi indo atrás dele na Otávio Rocha que realizei mais duas entrevistas nesta rua, com deficientes visuais que também usam a mesma via para desempenhar suas atividades. São eles: Seu Cazuza e Dona Ilma.

\title{
A ambiência do centro
}

Fragmentos de diário de campo:

\begin{abstract}
"O comércio informal realizado no centro de porto Alegre cria alguns pontos famosos que servem de referência tanto para os "clientes", quanto para os vendedores. A esquina democrática serve de ponto de referência para o meu grupo pesquisado. Quando quero encontra o Wilson o primeiro local ao qual me dirijo é em direção a esta esquina, se ele não está ou não veio trabalhar, alguém estará lá para me dar informação.

A esquina democrática serve de referência porque sempre há lá algum deficiente visual que irá dar alguma informação para mim, o grupo dos vendedores de bilhete a qual pertence o Wilson é grande, apesar dele confessar que só com uns quatro bilheteiros ele tem maior amizade, todos se conhecem através da profissão desenvolvida no local. A esquina democrática funciona como um ponto de partida para esse grupo. Uma vez quando eu estava chegando na esquina democrática, vi que um deficiente visual andava, em plena rua da praia com um grande número de bilhetes nas mãos. No meio da multidão percebi que lá embaixo das pilastras estava um grupo de deficientes visuais que aguardavam ansiosos a chegada do colega. Wilson estava lá embaixo das pilastras".
\end{abstract}

A rua Otávio Rocha é uma paralela à rua dos Andradas, no centro de Porto Alegre. Chego até ela descendo o último quarteirão da rua Floriano Peixoto. Esta rua possui um enorme canteiro central que a divide. Em cima deste canteiro há um grande número de floriculturas, além de bancas de revista, desenhistas, cocadeiros e palhaços que ficam imitando quem passa por lá. Esta rua também é ponto de partida de lotações que dirigem-se para bairros de classe média alta, como por exemplo, para o bairro Mont' Serrat. A maioria de lojas que localizam-se nela vendem eletrodomésticos, e assim como a rua Floriano Peixoto, a arquitetura das sobrelojas é bastante antiga em contraste com a parte de baixo, onde localizam-se as lojas. $\mathrm{Na}$ esquina com a rua Vigário José Inácio há uma grande loja que vende CDs, esta emite um 
som tão alto que sonoriza a rua quase que inteira, chama-se Multisom. O tráfego da rua consiste basicamente em lotações, carros forte, devido aos bancos que aí se localizam, e táxis, que tem por objetivo usar a saída de baixo do centro. A rua tem tanto pedestre andando livremente que só sabe que é uma rua quando passa algum carro

O centro da cidade de porto Alegre é muito grande. Apesar disto a concentração de deficientes visuais que trabalham no local, com venda de bilhetes, concentram-se preferencialmente nestas ruas descritas. Torna-se muito difícil encontrar deficientes vendendo bilhetes, por exemplo, na Praça da Alfândega. Quando perguntei para o Wilson Kemer, integrante do grupo de bilheteiros de Wilson, meu entrevistado, porque a preferência pela esquina democrática e não a Praça da Alfândega, ele disse-me que a Praça da Alfândega é muito longe, e caso ele consiga boas vendas, terá que voltar para comprar bilhetes na Lotérica que sempre compra, pois já conhece o dono, e esta situa-se na Esquina Democrática. Na realidade o grupo de Wilson, por atuar a bastante tempo na Esquina Democrática, desenvolveu uma rede de amizade, com os vendedores das lotéricas, onde conseguem descontos, pelo motivo de se tornarem clientes exclusivos destas lojas. Então preferem não se afastar muito das lojas onde compram seus bilhetes.

Mas o centro de Porto Alegre passou por muitas mudanças durante o tempo. Este centro que descrevi como sendo um ponto de convergência para diversos trabalhadores da economia informal, provenientes na maioria das vezes da região metropolitana da capital, que disputam cada palmo de calçada deste território como oportunidade única para aumentar suas rendas, nem sempre foi assim. Através dos trabalhos de Patrícia Rodolpho e Sandra Jatahy Pesavento, dá para se ter idéia de como este local passou por transformações modernizadoras e estéticas, tanto na parte física quanto nas pessoas que o freqüentaram durante o tempo. "Na segunda metade do século XIX, Porto Alegre passou por
significativas transformações nos seus aspectos urbanos: era a modernização e o
início da feição burguesa da cidade, quando as praças e as ruas centrais de Porto
Alegre perderam suas antigas formas e ganharam novo perfil, sendo que a rua da
Praia(Andradas) era o eixo de efervescência urbana da época"
(PESAVENTO,1992)

"Até a Segunda Guerra Mundial a Rua da Praia (Andradas) estava recoberta das influências européias, onde os cafés e o footing da rua da Praia eram a vitrina, os entretenimentos possibilitavam uma forma de exposição dos indivíduos, e onde o centro de Porto Alegre era um lugar chique por excelência" (RODOLPHO, 1998) 
"Entretanto, a Rua da Praia perdeu muitos dessas suas características glamourosas. Atualmente, como ocorre na maioria das grandes cidades brasileiras, a Rua da Praia revela a descaracterização dos estilos arquitetônicos empreendidos, e o comportamento primordialmente funcional de seus usuários. Ao invés dofooting da Rua da Praia, prestigiado pelos moradores da cidade até a década de 50, observa-se hoje o movimento de uma população inteira vinda de vários bairros com destino ao trabalho, ou em busca de serviços diversos. A proliferação do comércio informal (camelôs, feirantes e músicos), os prédio antigos desgastados pelo tempo, em meio a outros estilos arquitetônicos bem mais funcionais, além das mudanças relativas ao estilo da indumentária para freqüentar este espaço são alguns dos aspectos estéticos importantes nos quais podemos detectar as transformações conseqüentes da passagem do tempo" (RODOLPHO, 1998)

\section{Conhecendo Wilson, Seu Cazuza e Dona Ilma}

Pesquisador: "Porque prefere este lugar para trabalhar dona Ilma?

Dona Ilma: Já estou acostumada, venho direitinho, desço do meu ônibus e venho direitinho. O pessoal daqui me cuida. Conhece o pessoal da rua? Já. O pessoal me apoia." "É porque eu pago água e luz e já não tenho mais nada. Tenho que fazer um bico para comer, beber, me calçar e me vestir".

Pesquisador: "E você mora onde?

Wilson: Canoas

P: E vem para cá como?

W: Todo dia de metrô. É um serviço de ótima qualidade principalmente para nós deficientes, porque eles nos prestam toda assistência. Por exemplo eu não ando de metrô sozinho, sempre tem sempre algum segurança comigo, que se comunica com os outros da próxima estação me dando todo apoio."

Fragmento de diário de campo:

"Na outra semana fui direto falar com seu Cazuza, este disse que não sabia quem eu era. Não tem problema falei, e comecei a explicar a respeito da minha pesquisa para ficar claro o que estava fazendo ali. Seu Cazuza meio sem entender continuou calado apenas me escutando. Após eu explicar o que estava fazendo ali, disse-me :

-Eu sei o que isso de colégio por causa da minha família, mas o que eu não entendo é qual é o significado do seu trabalho.

Insistia muito em saber qual era o significado de alguém andar por aí batendo fotos dos outros, qual o significado que isso tinha. Quem ganhava com isso. Não deixou eu tirar fotos suas.

Na semana seguinte seu Cazuza me falou de novo de suas dores na mão. Mostrava-me o dedo dizendo que não agüentava mais de dor. Perguntei se ele me conhecia ele disse que estava começando a reconhecer minha voz, e que eu era o cara das fotos que ele não entendia o significado. Falou que já iria tomar um café no Haiti, pois estava com fome. Perguntei onde era o Haiti e ele me respondeu se eu não estava enxergando a placa que indicava a entrada do bar, foi quando avistei do outro lado da rua a entrada do estabelecimento com o nome descrito. Seu Cazuza disse-me que todos ali o conheciam e que sempre tomava café ali antes de ir para casa."

Forma desenvolvidas três entrevistas no centro da cidade com deficientes visuais que lá trabalham, nesta segunda parte da minha pesquisa. Seu Cazuza, Wilson e Dona Ilma foram os entrevistados. Responderam minhas perguntas no local de trabalho, ou seja, no centro de Porto Alegre, na rua Otávio Rocha. Entre os três apenas com o seu Cazuza não consegui realizar uma entrevista formal, devido a sua 
idade e por ele não conseguir entender o que eu queria com tal procedimento. Mas mesmo assim através de conversas consegui tirar-lhe informações interessantes que foram aproveitadas no meu trabalho.

As semelhanças nos perfis de meus entrevistados também existe no segundo grupo. Tanto Wilson, como seu Cazuza ou a dona Ilma, os três, não moram na cidade de Porto Alegre, mas sentem-se como moradores desta. São moradores da região metropolitana da cidade, Canoas, Viamão e Alvorada. Dependem de transporte coletivo para se deslocarem até seus locais de trabalho, por motivos de não possuírem condução própria.

O mais novo é o Wilson, tem 39 anos, e o mais velho é o Seu Cazuza, 86 anos. Todos tem filhos e família, e trabalham no centro da cidade há mais de doze anos. Apenas o Seu Cazuza que esmola, mas segundo ele, já foi vendedor, os outros dois trabalham com vendas, Wilson vende bilhetes lotéricos e Dona Ilma vende lixas. Cabe salientar que estas três atividades são realizadas na mesma rua, apenas distinguindo o local onde são efetuadas. Os três recebem uma pensão, um salário, e a atividade informal realizada no centro da cidade vem a se somar a este saldo, na intenção de melhorar seus níveis de vida, e também, como forma de exercer alguma atividade profissonal.

Todos se sentem contentes com o local de trabalho, e declaram não querer trocar o centro da cidade por algum outro local de Porto Alegre. Apenas nos fins de semana que baixa o movimento no centro eles deslocam-se para outros pontos da cidade, como por exemplo, o Brique da Redenção no Parque Farroupilha, na busca de um ambiente com muitas pessoas para que a possibilidade de venda aumente.

O nível de escolaridade do grupo também é muito parecido, sabem assinar apenas o nome. Não possuem o hábito da leitura em braile.

Seu Cazuza não nasceu cego, após um acidente de trabalho que tornou-se deficiente visual. Acidente este que aconteceu na rua Otávio Rocha, quando seu Cazuza era pião de construção e trabalhava nas obras do Banco Bradesco, que estava em construção. Após o acidente seu Cazuza ficou impossibilitado de trabalhar, pois, quebrou as pernas, os braços, algumas costelas, furou um olho e perdeu o outro queimado, em uma queda de um dos andares da construção. Hoje pede esmolas na mesma rua onde aconteceu o acidente, e adora mostrar sua carteira de trabalho e contar esta história.

Dona Ilma se sente tão a vontade nesta rua que carrega consigo uma cadeira de praia que coloca onde prefere sentar-se. Os lojistas já a conhecem, e perguntam a 
ela quando o sol está incomodando, para que mude de local sua cadeira.

A religião evangélica é seguida por Seu Cazuza e Wilson, Dona Ilma não referiu ter preferência por alguma.

As respostas das entrevistas feitas com os deficientes do centro, diferenciaram-se totalmente da respostas que me foram dadas pelo André e pelo Renato sobre a relação com a cidade. Os deficientes visuais do centro da cidade tinham uma imagem, no mínimo, mais agradável da cidade. Diferente do primeiro grupo entrevistado, notei que estes deficientes do centro conviviam de uma forma harmônica com a mesmas partes da cidade que o André e o Renato têm aversão. Ou seja, convivem em harmonia com partes públicas, ruas lotadas, onde muitas pessoas trafegam indo e vindo de seus trabalhos.

As ruas do centro da cidade, por exemplo, que o André me dizia ser insuportável de caminhar devido ao desrespeito dos demais transeuntes, e que o Renato coloca como obstáculo para o seu deslocamento até o trabalho, a Dona Ilma leva uma cadeira para sentar- se devido ao cansaço de ficar de pé ao vender suas lixas. E o impressionante é que isso ocorre na mesma rua em que o Renato passa todos os dias para ir ao trabalho. Notei que realmente são opostas as imagens criadas das mesmas ruas pelos integrantes dos grupos entrevistados. Uma vez estava conversando com seu Cazuza quando repentinamente senti uma dor muito forte nas costas. Virei e olhei para ver o que havia me atingido, e coincidentemente era o Renato indo trabalhar que acabava de me dar uma bengalada nas costas. No momento achei engraçado e não falei nada para ele, continuei conversando com o seu Cazuza, o pior foi que o Renato com toda sua educação aristocrática pelotense não me pediu desculpas, e continuou andando.

\section{O referencial teórico}

É preciso mostrar que os dados obtidos em campo e as conclusões que tirei destes, foram analisadas através de um referencial teórico que conceitua a vida metropolitana como ponto de interseção de vários mundos, que através de conteúdos novos e antigos individualizam-se por uma diversidade de combinações das afiliações dos indivíduos a grupos diferentes, através de interações a que estão sujeitos.

"A cidade assume, assim, um lugar estratégico como locus privilegiado para reflexão antropológica em sua busca de aprender, a partir de uma perspectiva compreensiva, tanto a comunicação que preside as formas de vida social no meio urbano, como nas multiplicidades e singularidades que encerram o vivido humano 
no interior deste espaço existencial criado pelo homem da civilização". (ECKERT e ROCHA, 1998)

Sendo assim, através do esforço empreendido para mapear os itinerários e as formas de sociabilidade, dentro deste espaço urbano tido como cidade, se pode atingir uma descrição simbólica do movimento das vidas que aí se processam. O que nos leva a ver a cidade como um espaço onde coexistem diferentes estilos de vida e visões de mundo.

\begin{abstract}
"Em decorrência, os espaços urbanos construídos e vividos, como objeto etnográfico, vão se revelando não meros reflexos de políticas urbanísticas, mas suportes de tradições e biografias de seus habitantes cujas narrativas expressam uma linguagem coletiva que comunica uma pluralidade de identidades e memórias, remetendo seus territórios aos pretextos e às manipulações humanas.

Neste sentido, os espaços públicos e/ou outros do domínio privado fornecem o suporte material de um investimento simbólico referido ao cotidiano afetivamente significativo de seus grupos sociais.” (ECKERT e ROCHA, 1998)
\end{abstract}

Dentro deste referencial teórico a cidade torna-se um objeto de estudo temporal, onde o tempo social é fruto de uma infinidade de trajetórias particulares, onde indivíduos escolhem, optam e tecem projetos dentro de um quadro de possibilidades socialmente valorizado.

"É através da sobreposição de tempos vividos e de tempos pensados pelos habitantes das grandes cidades, reencontrados na vida do dia-a-dia, que se pode pesar o tempo social como duração." (ECKERT e ROCHA, 1998)

É importante lembrar que urbanização, no Brasil e na América Latina, partiu através de políticas de modernização, muitas vezes estas tendo sentido higienizador, mas que não conseguiram ordenar o crescimento de suas cidades, onde problemas como densidade populacional, fluxo migratório e saneamento básico aparecem como constantes para uma população de baixa renda que vive em invasões, assentamentos e favelas.

Conceito antropológico que unifica este quadro teórico, é o conceito de sociedade complexa usado por Gilberto Velho. Esse conceito fundamenta uma sociedade onde a divisão social do trabalho, advinda da Revolução Industrial e suas inovações tecnológicas, é capaz de fazer o homem moderno habitar cidades onde a distribuição de riqueza delineia categorias sociais em seu seio.

Outro conceito que vem junto a noção de complexidade é a idéia de uma heterogeneidade cultural desenvolvida por Ruben Oliven (1980) seguindo os ensinamentos da Escola de Chicago, notamente de Park, Simmel, Weber. Conceito entendido como a coexistência, harmoniosa ou não, de uma pluralidade de 
tradições cujas as bases podem ser ocupacionais, étnicas ou religiosas, por exemplo. Isso faz com que o contato com círculos e grupos distintos afetem vigorosamente a visão de mundo e o estilo de vida de indivíduos situados em determinados segmentos sociais, deixando ver que em sociedades modernas a complexidade do desenvolvimento intelectual e emocional não está definido unicamente ao segmento social a qual o indivíduo pertence. Uma das formas de dar conta deste processo é justamente buscar conhecer a partir do estudo etnográfico a forma como os sujeitos se relacionam com sua cidade.

A noção de indivíduo ocidental, presentes nas sociedades complexa, dá a base de sustentação para uma dimensão consciente da vida social. A idéia de que os indivíduos escolhem e podem escolher é o ponto de partida para se pensar no desenvolvimento de projetos individuais nas sociedades complexas. Esses projetos são elaborados e construídos, por indivíduos, em função de experiências sócioculturais, de vivências e interações interpretadas, e não são completamente subjetivos. São elaborados através de um campo de possibilidades histórico e cultural onde o indivíduo está inserido, e aparecem como tentativa de dar sentido a uma experiência particular. .Portanto, quanto maior for à consciência da individualidade fabricada dentro de uma experiência cultural específica, esta corresponderá a uma maior elaboração de um projeto individual. Assim como sua avaliação, que será construída através de estratégias de metas, e de etapas temporais para o desencadeamento destas

A modernidade da vida metropolitana consiste nesta variedade de estímulos que permite, ao mesmo tempo, um pluralismo de grupos e individualidades de projetos.

Outro conceito que está sendo usado é o de cultura tomado por Clifford Geertz (1983), este é articulado como uma produção simbólica e um sistema de símbolos compartilhados, que dão indicações e contornos de grupos sociais específicos. Entender cultura como um código e não como um repositório estático de hábitos e costumes, mas o próprio elemento onde a vida social se processa, a simbolização.

Desta forma é que o autor fala de ethos, quando refere-se a aspectos morais e valorativos e, visões de mundo, quando fala de aspectos cognitivos existenciais. A descrição densa é a etnografia desenvolvida pelo antropólogo, e segundo o autor, uma descrição densa de qualquer cultura só é possível pensando esta como sendo um sistema entrelaçado de signos interpenetráveis, um contexto onde pode-se dentro dele serem descritos de formas inteligíveis, por exemplo, os acontecimentos sociais, os comportamentos e as instituições (GEERTZ, 1983). 


\section{Conclusão}

A análise que pode-se sugerir a partir dos dados apresentados, através de um referencial teórico sobre o problema de pesquisa que foi levado aos dois grupos entrevistados, foi a de que os deficientes visuais de classe média imaginam a cidade através de uma distinção entre dois ambientes.

Um ambiente público que segundo eles não oferece a menor autonomia ou segurança aos portadores de deficiência visual, muito pelo contrário, este tipo de ambiência é preferencialmente evitado por estes transeuntes especiais. Quando o André me diz "que a cidade de Porto Alegre não presta", este está referindo-se as partes públicas da cidade, ou seja, qualquer parte que fique fora de sua casa e da proteção de seus amigos, onde ele dependa da ajuda de estranhos para atravessar uma rua, por exemplo. Nestes ambientes além da falta de compreensão, e de ajuda, dos transeuntes que não deixam livre o passeio público, deficientes visuais de classe média sentemse discriminados também através das políticas urbanas que não lhes beneficiam. Seja pela falta de rampas adequadas para subirem calçadas ou pela falta de corrimãos, ou mesmo pela ausência de leis que proíbam restaurantes de ficarem com seus toldos levantados sobre a calçada.

Um discurso intelectual de um deficiente que "não vê sua individualidade respeitada no meio público", Assim André conceitua a cidade de Porto Alegre como "uma cidade cheia de pega-cegos". Elementos que atrapalham o passeio de um deficiente visual pela cidade, ficando incluído como tais, orelhões, caixas postais, garagens abertas, toldos de bares e carrinhos de papeleiros, anteparos estes que não podem ser percebidos através da bengala que rastreia o chão que será pisado.

Renato com seu discurso intelectual-acadêmico, fala que não é Porto Alegre, mas sim a cidade que por si só é uma contradição na forma pela qual os homens deveriam viver. Através de sua internalização de um ethos campestre este entrevistado fala da falta de relação com a natureza que há na cidade, e dos problemas que isso trás para as pessoas que aí moram. Concorda com o André quanto a negligência por parte dos governantes para com o grupo de deficientes que usa as vias públicas e também destaca seu constrangimento de vir a ser motivo de piadas quando saí de casa.

A classificação feita pelo André a respeito da imagem que ele tem da cidade de Porto Alegre, como sendo feita através uma estética funcional, representa muito bem o discurso classe média dos entrevistados citados na Parte I. Para este entrevistado, o que conta depois que se tornou um deficiente visual é a funcionalidade dos espaços na cidade. 
Transportes coletivos, orelhões, carrinhos de papeleiros, falta de rampas, falta de sinalização, risos, piadas, brincadeiras e ainda a deficiência, tudo isso, faz com que deficientes visuais pertencentes a classe média afastem-se das partes mais dinâmicas da cidade em contraste à segurança obtida em seus lares. Nestes ambientes privados deficientes visuais encontram o conforto de uma decoração que privilegia seus deslocamentos, além de encontrar a compreensão de familiares e objetos desenvolvidos especialmente para deficiência visual. A proteção e o respeito encontrados no lar e no trabalho, não é sentida nas ruas de Porto Alegre. $\mathrm{O}$ contraste destes dois ambientes se mostra como a imagem que o primeiro grupo entrevistado faz da cidade de Porto alegre, nos remetendo a considerar a importancia da diferença entre espaço privado que traz segurança, e o espaço publico, onde estes informantes estao expostos aos constrangimentos de uma cidade urbana que negligencia sua deficiencia.

\section{Como podemos concluir com Roberto da Matta:}

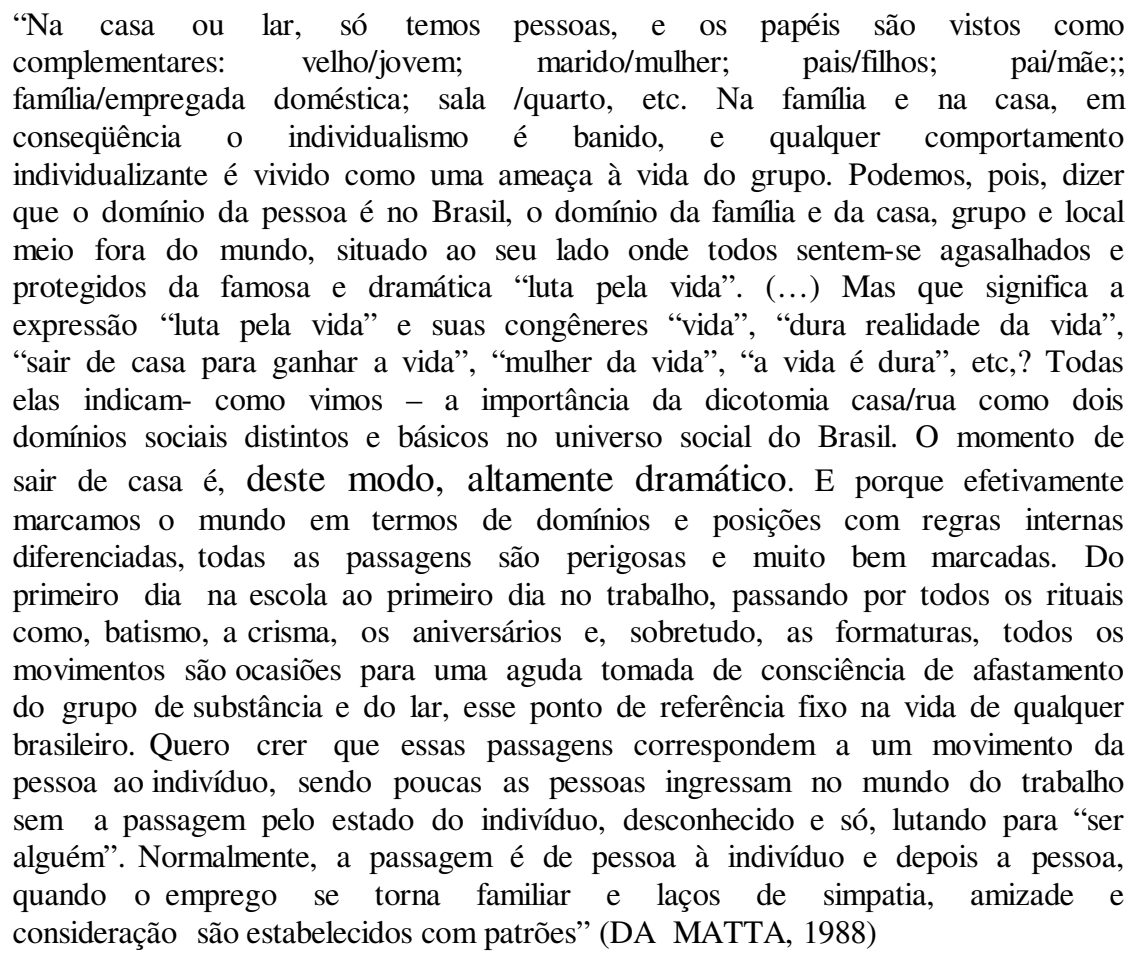

Contrariamente, o segundo grupo entrevistado, mostra que a imagem que os bilheteiros, que trabalham no centro da cidade de Porto Alegre têm deste território, é uma imagem onde as partes públicas da cidade surgem como uma forma de se ganhar um dinheiro a mais que irá somar-se a aposentadoria miserável paga pelo governo. São deficientes que usam os mesmos locais evitados pelo meu primeiro grupo para desenvolver atividades comerciais, de certa forma dependem 
desta partes da cidade. São na maioria moradores da periferia de Porto Alegre que têm como imagem desta, certos pontos de efervescência urbanas onde há possibilidade de vendas, trabalho e dinheiro. Cumprem horário como qualquer trabalhador e, diferente dos entrevistados pertencentes ao primeiro grupo, criam ligações afetivas com estas partes da cidade, assim como com as pessoas com que convivem nestes ambientes.

Dependem de transporte coletivo e não acha isso uma tarefa tão insuportável assim, pelo contrário, através de laços pessoais desenvolvem amizades com motoristas de ônibus e trocadores que os auxiliam nos deslocamentos. Criam relações com gerentes de restaurantes do centro da cidade, e estes, separam locais especiais para eles almoçarem. Ou seja, através da necessidade do trabalho e das relações de amizades desenvolvidas com o passar do tempo, estes deficientes têm uma imagem da cidade que é bastante diferenciada da imagem criada pelo primeiro grupo. Seus vínculos pessoais de relação e a solidariedade recebida por parte de comerciantes das zonas centrais, amenizam a má imagem dos espaços público da cidade, apesar de muitas vezes, não se sentirem respeitados por políticas públicas de urbanização, mas trazem na necessidade de sobrevivência do ganha pão diário, a imagem da cidade de Porto Alegre como o local adequado para tal fim.

Desta forma a cidade moderna apresenta-se como este foco de convergência de visões de mundo tão distantes mas que dividem o mesmo espaço territorial, onde cada morador a vê com uma finalidade própria. Por isso talvez seja possível que o Renato e o Seu Cazuza dividam a mesma calçada apesar de formarem opiniões completamente divergentes a respeito do espaço que compartilham. Renato mora a algumas quadras de distância do local de trabalho do Wilson, seu Cazuza e dona Ilma.

Além da metodologia citada, no decorrer do texto, usei o recurso fotográfico para auxiliar na composição de meus diários de campo. Estas imagens foram realizadas com os deficientes que compõem minhas narrativas. São dados de campo que estão sujeitos ao mesmo quadro teórico usado na pesquisa, ou seja, estas imagens somadas a narrativa etnográfica, assim como, aos depoimentos dos próprios personagens, auxiliam a reconstrução sócio cultural do ambiente citado. Tornando-as dados de grande valor na construção e reflexão da pesquisa. Foram realizadas com os entrevistados Wilson Borba, Ilma dos Santos e seu Cazuza, todos estavam em local horário de trabalho e aceitaram ser fotografados. 


\section{Referencias}

ARIES, Philippe. "A família e a cidade". In: VELHO, Gilberto e FIGUEIRA, Servulo. Família, psicologia e sociedade. RJ, Ed. Campus, 1981. Ler p. 13 a 23

CANEVACCI, Massimo. "São Paulo e Nova York dentro de Lévi-Strauss". In A cidade polifônica. Studio Nobel. Ler p. 77 a 95.

DA MATTA, Roberto. Carnavais, malandros e heróis; Rio de Janeiro: Zahar Editores, 1988.

ECKERT, Cornelia e ROCHA, Ana Luiza Carvalho da, "Premissas para o estudo da memória coletiva no mundo contemporâneo sob a ótica dos itinerários de grupos urbanos e suas formas de sociabilidade": Revista Margem Tecnologia, Cultura. Faculdade de Ciências Sociais - PUC - SP, EDUC- FAPESP. Numero 8. 1998. P. 243 à259.

GEERTZ, Cliford, A interpretação das cultura; Rio de Janeiro: Ed Guanabara, 1983

OLIVEN, Ruben. Urbanização e mudança social no Brasil. Petrópolis, Vozes, 1982

PARK, Robert E. "A cidade: sugestões para a investigação do comportamento humano no meio urbano". In: VELHO, Otávio G. (org). O fenômeno urbano. $4^{\mathrm{e}} \mathrm{ed}$. Rio de Janeiro, Zahar, 1979

PESAVENTO, Sandra Jatahy, O espetáculo da rua; Porto Alegre: Ed. Da Universidade UFRGS, 1992

RODOLPHO, Patrícia, "Encontrando imagens na e da Rua da Praia: Problemas e descobertas de uma etnografia": Monografia de bolsista técnica Cnpq no ambito do Projeto de Pesquisa Integrado : “ Estudo Antropológico de Itinerários Urbanos, Memória Coletiva e Formas de Sociabilidade no Meio Urbano Contemporâneo"coordenado e orientado por Cornelia Eckert e Ana Luiza Carvalho da Rocha, 1998. SANTOS, C. N. A cidade como um jogo de cartas. São Paulo, Projeto Editores, 1988. Cap. 4, pp. 31-39 e cap. 5, 39-49

SIMMEL, Georg. "A metrópole e a vida Mental" In: VELHO, Otávio G. (org).

O fenômeno urbano. 4e ed. Rio de Janeiro, Zahar, 1979.

VELHO, Gilberto, A utopia urbana; Rio de Janeiro: Zahar editores, 1973

VELHO, Gilberto, Individualismo e cultura; Rio de Janeiro: Ed.Jorge Zahar, 1999.

VELHO, Gilberto, Subjetividade e sociedade; Rio de Janeiro: Jorge Zahar Editor, 1989.

WEBER, Max. "Conceito e categorias da cidade. In: VELHO, Otávio Guilherme (organizador). O fenômeno urbano. $4^{\mathrm{e}}$ ed. Rio de Janeiro, Zahar, 1979.

WIRTH, Louis. "O urbanismo como modo de vida". In: VELHO, Otávio G.

(org). O fenômeno urbano. 4e ed. Rio de Janeiro, Zahar, 1979.

ZALUAR GUIMARAES, Alba. Desvendando Máscaras Sociais. 